\title{
Memory suggestibility as an example of the sleeper effect
}

\author{
JOE UNDERWOOD and KATHY PEZDEK \\ Claremont Graduate University, Claremont, California
}

\begin{abstract}
This study incorporates findings on both the sleeper effect and the suggestibility of memory and assesses the effect of source credibility and time delay on memory suggestibility. Subjects viewed a sequence of slides with four target items. A narrative followed, containing a misleading description of two target items; the other two items served as controls. The source of the narrative was attributed to either a 4-year-old boy (low-credibility source) or a memory psychologist (high-credibility source) who described the slides. A recognition memory test followed $10 \mathrm{~min}$ or 1 month later. The subjects in the low-credibility source condition falsely recognized significantly more misleading items in the delayed condition than in the immediate condition; in the high-credibility condition, the number of falsely recognized misleading items was high and did not differ between the delayed and the immediate conditions. This significant interaction between source credibility, time, and misled/control conditions on the rate of falsely recognizing misled items suggests that, with the passage of time, item and source information become less strongly associated in memory. The cognitive processes underlying the sleeper effect appear to be similar to those underlying memory suggestibility.
\end{abstract}

Psychological interest in the suggestibility of memory has increased dramatically in the past decade. This interest is due to both the concerns of the legal system regarding the reliability of child witnesses (Bottoms \& Goodman, 1996; Ceci \& Bruck, 1993) and the concerns about the validity of claims of recovered memories (Loftus, 1993). Although many memory researchers have reported that memories can be suggestively influenced (Belli, Lindsay, Gales, \& McCarthy, 1994; Hyman, Husband, \& Billings, 1995; Loftus \& Palmer, 1974; Loftus \& Pickrell, 1995; Pezdek, 1977), constraints on the construct of suggestibility have been noted (Ceci \& Bruck, 1993; Lindsay, 1933; Pezdek, Finger, \& Hodge, 1997; Pezdek \& Greene, 1993; Pezdek \& Roe, 1994). This study examined the interaction of two such constraints on suggestibility - source credibility and time delay.

Although the effect of the interaction of source credibility and time delay on the suggestibility of memory has not been investigated, the effect of this interaction on communication effectiveness has been thoroughly researched. In a study by Hovland and Weiss (1952), subjects evaluated two presentations, one given by a communicator of high credibility and the other given by a communicator of low credibility. Although the presentations were identical, the subjects rated the high-credibility communicator as significantly more effective than the lowcredibility communicator. When the researchers tested the subjects 4 weeks later, however, the ratings of the low-

This research was conducted as J.U.'s masters thesis, under the supervision of K.P. J.U. thanks Mette Kurth for her patience and support throughout this project and for her talented editing. Correspondence should be sent to K. Pezdek, Department of Psychology, Claremont Graduate University, Claremont, CA 91711 (e-mail:kathy.pezdek@cgu.edu). credibility communicator had increased, and the difference between the two credibility conditions was no longer significant. The researchers labeled this phenomenon the sleeper effect. This effect occurs when the impact of information from a source low in credibility increases over time (Hovland, Lumsdaine, \& Sheffield, 1949). Although many researchers rejected the sleeper effect when they failed to replicate the findings of Hovland and Weiss (see, for example, Gillig \& Greenwald, 1974), many researchers have since replicated the effect when carefully controlling their procedures (Hannah \& Sternthal, 1984). Currently, researchers have accepted the existence of the sleeper effect and have moved ahead to focus on why the effect occurs and under what conditions (Mazursky \& Schul, 1987).

The dominant interpretation of the sleeper effect is based on the availability-valence hypothesis. According to this hypothesis, the cognitive availability of relevant issues at the time of recall determines how an individual will judge the effectiveness of a message. The availability of the issues depends both on the recency of information and on the degree of cognitive elaboration (e.g., the number and type of related associations that are activated at encoding). As posited by Hannah and Sternthal (1984), when an individual reads a message, the individual encodes two potential pieces of information into memory - the message and the credibility of the source of the message. The relative availability of both pieces of information, however, is dependent on the actual encoding process. Specifically, if the information is elaborated on during encoding, the information becomes relatively more available for later recall. The elaboration is particularly effective if the individual uses the self as a reference when encoding the information (Mazursky \& Schull, 1987). 
The elaboration becomes particularly relevant as more time passes from the initial encoding to the time of recall. If an individual recalls a message soon after reading it, the recency of the encoding ensures that the message and the source are available in memory. With the passage of time, however, the message and the source become less strongly associated in memory. The elaborated message, then, will have a relatively greater chance of being available than the nonelaborated source, so that, when the message is recalled, the source is less likely to be remembered (Hannah \& Sternthal, 1984; Mazursky \& Schul, 1987). In the study by Hovland and Weiss (1952), subjects initially rejected the low-credibility communicator, because the message and its source were strongly associated in memory. After a month, however, the message and its source were less strongly associated, so the subjects did not reject the low-credibility communicator.

The availability-valence hypothesis was developed to explain the impact of time and source credibility on communication effectiveness. In this study, however, we apply these underlying concepts to the study of memory suggestibility. When misleading information is suggested to subjects, this increases the probability that they will later falsely recognize this information as true. The probability that subjects will be misled by the suggested information is greater if the source of the misleading information is attributed to a high-credibility source rather than to a low-credibility source. Dodd and Bradshaw (1980) showed subjects a video of an automobile accident. Later, each was provided a transcript of an eyewitness account that contained three false presuppositions. This account was attributed either to an innocent bystander (neutral source) or to the driver of the car that caused the accident (biased source). Subjects incorporated the presupposition into memory if they thought the source of the presupposition was neutral, but not if they thought the source was biased. Similarly, Smith and Ellsworth (1987) reported that adults were more likely to be misled by a high- than by a low-credibility source.

Lampinen and Smith (1995) found similar results when they showed a videotaped interview to children ranging from 3 to 5 years of age. The interview contained either an adult (high-credibility condition), a silly adult (lowcredibility condition), or a child (low-credibility condition), each of whom provided either misleading information or unbiased information. In the high-credibility condition, the children were misled; there was a significant difference in accuracy between the children in the misled condition and those in the control condition. In the low-credibility condition, there were no significant differences in accuracy between the misled and unbiased conditions. Thus, when the subjects were provided with misleading information, they were more likely to be suggestively influenced by the misleading information if the source of the information was credible. In contrast, the subjects were not suggestively influenced by the misleading information if the source of the information was not credible. Similar findings have also been reported by Ceci, Ross, and Toglia (1987), with children as subjects.

Although researchers have shown, then, that source credibility does affect memory suggestibility, no researchers have studied the effect of the interaction of source credibility and time delay on memory suggestibility. In this study, it is posited that, much as in the sleeper effect, in the suggestibility paradigm, a misleading item and its original source will become less strongly associated in memory as time passes. As the association weakens with time delay, the probability that subjects will be misled by information suggested by a low-credibility source will increase and approach the probability of being misled by information suggested by a high-credibility source. The probability that subjects will be misled by information suggested by a high-credibility source is predicted to be similar in the immediate and delayed test conditions.

In this study, the past findings of both the sleeper effect and memory suggestibility studies were incorporated in order to examine the effect of source credibility and time delay on memory suggestibility. Specifically, subjects viewed two slide sequences that each contained two target slides. After the slides were presented, the subjects read a narrative that contained a misleading description of two of the target slides (one for each slide sequence). The source of the narrative was attributed to either a high-credibility source or a low-credibility source. Half of the subjects completed a recognition test $10 \mathrm{~min}$ later, and the other half completed a recognition test 1 month later. The major prediction was that the number of falsely recognized misleading items would be greater in the misled condition than in the control condition and that the difference between the rate at which the subjects falsely recognized the misleading items in the misled verses the control condition would be greater in the delayed condition than in the immediate condition for the low-credibility source but would not differ between the delayed condition and the immediate condition for the high-credibility source.

\section{METHOD}

\section{Subjects and Design}

The subjects were 111 undergraduate students from colleges in the metropolitan Los Angeles area. All students participated in a classroom setting. The subjects ranged in age from 18 years to 33 years $(M=19.76$ years, $S D=2.90$ ); 61 were female, 47 were male, and 3 did not specify gender. The design was a 2 (source credibility) $\times 2$ (time) $\times 2$ (misled vs. control condition) mixed factorial design, with the first two factors varied between subjects. Each subject received both misled and control items. The subjects participated in groups, each of which was randomly assigned to one of four conditions arrived at by combining the first two variables. The numbers of subjects in these groups were as follows: high-credibility immediate test, $n=31$; high-credibility delay test, $n=25$; low-credibility immediate test, $n=28$; and low-credibility delay test, $n=27$.

\section{Procedure}

The procedure consisted of a presentation phase, in which two slide sequences were presented; a suggestion phase, in which two postevent narratives were read; and a recognition memory test phase. Prior to the 
presentation phase, the subjects were told that they would view a sequence of slides and that afterward they would be asked questions about what they saw. Each group of subjects was presented both slide sequences, counterbalanced across groups for order of presentation. The slides were presented at a rate of $3 \mathrm{sec}$ each. There was a brief break between presenting the two slide sequences that was only long enough for changing slide trays. After viewing both slide sequences, the subjects completed a $10-\mathrm{min}$ distractor task and were then read the two narratives, one after the other, without a break. They were instructed to visualize the slides while reading the narrative, in order to foster cognitive elaboration of the suggested information. A different 10 -min distractor task followed the suggestion phase. The subjects in the immediate test condition then completed the recognition memory test. The subjects in the delayed test condition completed the recognition memory task 1 month later. In all conditions, the researcher stressed that the subjects should not talk to each other about the slides, because they would be asked questions about the slides at another time.

\section{Materials}

The presentation slide sequence. Two slide sequences developed by Pezdek and Roe (1995) were used. One sequence of 26 photographs depicted a young woman preparing and baking a cake. She mixed ingredients, used various utensils and containers, and opened various doors, cabinets, and drawers. The other sequence of 26 slides depicted a man walking around a construction site as he prepared to work on a house. He carried and used various tools, toolboxes, and other construction equipment. There were two target slides in each sequence. In the kitchen sequence, the two target slides were (1) a picture of the women opening a drawer and pulling out a spoon and (2) a picture of the women opening a cabinet and pulling out a plate. In the construction sequence, the two target slides were (1) a picture of the man reaching down and picking up a hammer and (2) a picture of the man bending down and picking up a brick.

The postevent narrative. In the suggestion phase, a narrative summarizing each of the two sequences was read by the subjects. Each of the two narratives contained a control description of one target slide and a misleading description of the other target slide, (the spoon was described as a fork or the plate was described as a cup, and the hammer was described as a screwdriver or the brick was described as a rock). The control description used the generic word something to describe the target item, so the actual target item was never repeated in the narrative. The assignment of each target item to the misled or control condition was counterbalanced across subjects. In the low-credibility source condition, the subjects were told, "The narratives were created by the fouryear-old son of the man and woman in the slide sequences. The child watched the slides and then told us what he remembered seeing. The narratives are a paraphrased version of what he had described." In the high-credibility source condition, the subjects were told, "The narratives were created by a memory psychologist who described the slide sequence as he slowly watched it."

The recognition memory test. A recognition memory test was completed by each subject. The test consisted of 12 questions, randomly arranged and presented in the same order to all of the subjects. Subjects responded yes or no to each question. Each of the four target slides was referenced by 3 test questions. The 3 questions were worded identically, except for a key word that referred to either (1) the target item ("Did the lady reach into the kitchen drawer and pull out a spoon?"), (2) the misleading item ("Did the lady reach into the kitchen drawer and pull out a fork?"), or (3) a foil item ("Did the lady reach into the kitchen drawer and pull out a knife?"). It was possible for subjects to respond yes to any number of the 3 test questions that referenced each target sequence. The test was presented in writing, and the subjects were instructed not to go back and change any answers, once a response had been marked.

\section{RESULTS}

Presented in Table 1 are the mean number of yes responses per subject for the misleading, target, and foil items, as a function of the source credibility, time, and misled/control conditions. The effects for each of the three types of test items were analyzed separately, using a 2 (source credibility) $\times 2$ (time) $\times 2$ (misled/control) mixed factorial analysis of variance (ANOVA). The level of significance for all tests is $p<.05$.

The major predictions involve the subjects' responses to the misleading test items. As predicted, the main effects of time and the misled/control condition were significant in the anticipated directions $[F(1,107)=34.52$, $M S_{\mathrm{e}}=15.95$, and $F(1,107)=39.12, M S_{\mathrm{e}}=13.95$, respectively]. The only other significant effect involving the responses to the misleading test items was the predicted interaction of source $\times$ time $\times$ misled/control $\left[F(1,107)=4.18, M S_{\mathrm{e}}=1.49\right]$. The interaction is presented in Figure 1. As predicted, in the low-credibility condition, the difference between the rate at which subjects falsely recognized the misled items as old in the misled versus the control condition was greater in the delayed condition than in the immediate condition. In the high-credibility condition, the difference between the rate at which subjects falsely recognized the misled items as old in the misled versus the control condition was relatively high and similar in the immediate and the delayed test conditions. Separate 2 (time) $\times 2$ (misled control) ANOVAs were conducted on the high- and lowcredibility conditions separately. Whereas the time $x$ misled/control condition interaction was significant in the analysis of the low-credibility condition $[F(1,52)=4.6$, $\left.M S_{\mathrm{e}}=2.4\right]$, this interaction was not significant in the analysis of the high-credibility condition $(F=1.03)$.

Separate 2 (credibility) $\times 2$ (time) $\times 2$ (misled/control) ANOVAs were also conducted on the responses to target and foil test items. As can be seen in Table 1, the accuracy rate for recognizing target items was relatively high. None of the effects involving the target items was significant, although the source $\times$ time $\times$ control $/$ misled interaction approached significance $\left[F(1,107)=2.86, M S_{\mathrm{e}}=\right.$

Table 1

Mean Number of "Yes" Responses Per Subject

on Recognition Test (Maximum Mean $=\mathbf{2 . 0 0}$ )

Misleading Items Target Items Foil Items

\begin{tabular}{ccccccccc} 
& & \multicolumn{2}{c}{ Misleading Items } & \multicolumn{2}{c}{ Target Items } & & \multicolumn{2}{c}{ Foil Items } \\
\cline { 3 - 7 } \cline { 6 - 8 } Source & Condition & Immediate & Delay & & Immediate & Delay & Immediate & Delay \\
\hline Low credibility & control & 0.18 & 0.34 & 1.39 & 1.22 & 0.21 & 0.37 \\
& misled & 0.54 & 1.33 & 1.14 & 1.48 & 0.21 & 0.56 \\
High credibility & control & 0.19 & 0.30 & 1.32 & 1.20 & 0.42 & 0.52 \\
& misled & 0.94 & 1.12 & 1.19 & 1.04 & 0.35 & 0.56 \\
\hline
\end{tabular}



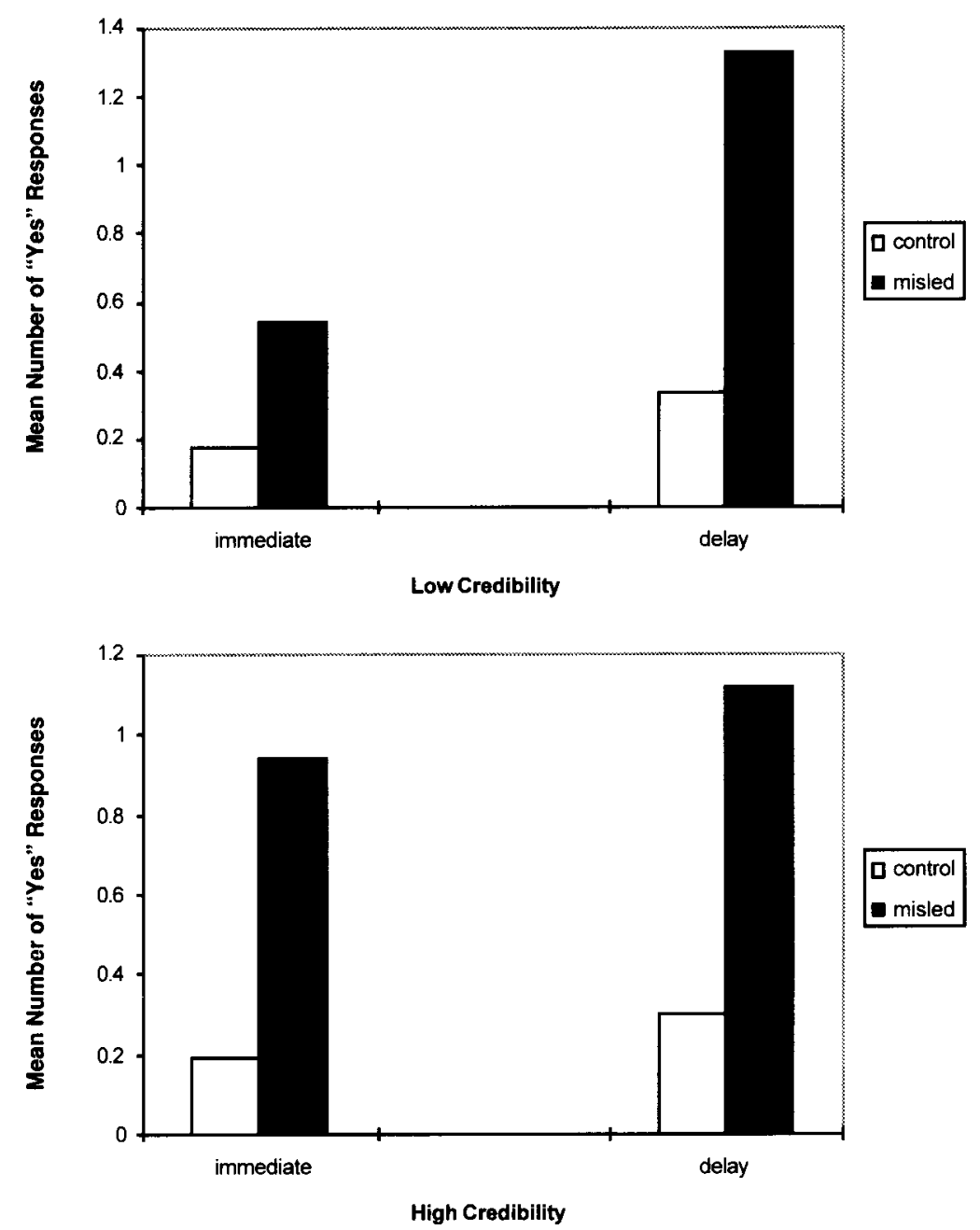

Figure 1. Mean number of yes responses to misleading test items per subject as a function of source credibility, time, and misled/control conditions (maximum score =

$1.01, p<.09]$. For the responses to the foil items, only the main effect of time was significant $[F(1,107)=7.22$, $\left.M S_{\mathrm{e}}=2.22\right]$.

The rate of responding yes was compared for misleading and foil test items in the misled condition only to assess whether the subjects were discriminating between their false alarm rate to these two types of new items. The number of recognized foil items $(M=0.41, S D=0.56)$ was significantly lower than the number of recognized misleading items $[M=0.97, S D=0.78, t(110)=6.12, p<.001]$. This suggests that the recognition of the misleading items specifically resulted from reading the intervening narrative, not from general effects of interference or simple memory decay. Otherwise, the number of recognized foil and misleading items, none of which were actually viewed in the slide sequence, would have been similar.

\section{DISCUSSION}

This study tested the hypothesis that misleading information and the source of the misleading information will become less strongly associ- ated as time passes, thus increasing the probability that a subject will be suggestively misled, especially by material from a low-credibility source. This hypothesis was confirmed. Consistent with the availabilityvalence explanation for the sleeper effect, when tested immediately, the subjects in the high-credibility condition falsely recognized more misleading items than did the subjects in the low-credibility condition. Because of the recency of the encoding, the misleading items were still associated with the source of the misleading information at the time of testing. In the 1 month delay condition, however, the subjects were more likely to be suggestively misled by the misleading narrative, with similar high false alarm rates for misleading items in both the low- and highcredibility source conditions. This result is attributed to the disassociation between item and source information in memory in the delayed condition. This significant interaction between source credibility, time, and misled/control conditions on the rate of responding yes to misled items suggests that, with the passage of time, item and source information become less strongly associated in memory. Thus, the cognitive processes underlying the sleeper effect appear to be similar to those underlying memory suggestibility.

The interpretation of memory suggestibility effects indicated above is related to the source-monitoring interpretation of Johnson and her colleagues (see, e.g., Johnson, in press). According to this view, in suggestibility experiments, at the time of test, subjects have access to representations of both the original information and the suggested information, but confuse which was presented when. According to Johnson, source 
memory will be reduced by anything that disnupts the binding of the semantic and the perceptual/contextual features of to-be-encoded information, at encoding or afterward. Although, in the present study, it is the credibility of the suggestive source that is forgotten over time, nonetheless, these two interpretations are similar in that both attribute suggestibility errors to the availability of source information at the time of test.

The impact that the sleeper effect has on memory, especially memory suggestibility, deserves careful consideration. In today's technological world, people are becoming daily consumers of massive amounts of information. Ideally, one would hope that people can discern between information that is highly credible and information that is not credible This study suggests that, initially, people can correctly discriminate between high- and low-credibility sources of information and are not likely to be misled by information from a low-credibility source. However, as time passes, their ability to resist being misled by information from a low-credibility source diminishes. This decrease in accuracy can have serious implications. In court cases, jurors should initially be able to correctly decide which evidence is credible and which evidence is not credible. In extremely long trials, however, jurors could be persuaded by misleading evidence from a low-credibility witness, especially if a knowledgeable attorney asks them to cognitively elaborate on this evidence during the trial to make it more memorable. Also, a month after initial viewing, less credible news programs, such as tabloid programs, could have the same impact as highly credible news programs, even when presenting deceptive stories. The scientific field is also not immune. If a scientist reads an article or study that includes misleading or misinterpreted results, the scientist may initially give little credence to the study. After the passage of time, however, the scientist might be discovered repeating the results of the study, without remembering the poor credibility of the source from which the information was obtained.

\section{REFERENCES}

Belli, R. F., Lindsay, D. S., Gales, M. S., \& MCCarthy, T. T. (1994). Memory impairment and source misattribution in postevent misinformation experiments with short retention intervals. Memory \& Cognition, 22, 40-54.

BotToMs, B. L., \& GoOdMan, G. S. (EDs.) (1996). International perspectives on child abuse and child testimony. Newbury Park, CA: Sage.

CeCl, S. J., \& Bruck, M. (1993). Suggestibility of the child witness: A historical review and synthesis. Psychological Bulletin, 113, 403-439.

Ceci, S. J., Ross, D. F., \& Togila, M. P. (1987). Suggestibility of children's memory: Psycholegal implications. Journal of Experimental Psychology: General, 116, 38-49.

DodD, D. H., \& BradshaW, J. M. (1980). Leading questions and memory: Pragmatic constraints. Journal of Verbal Learning \& Verbal Behavior, 19, 695-704.
Gillig, P. M., \& Greenwald, A. G. (1974). Is it time to lay the sleeper effect to rest? Journal of Personality \& Social Psychology, 29, 132-139.

HanNah, D. B., \& Sternthal, B. (1984). Detecting and explaining the sleeper effect. Journal of Consumer Research, 11, 632-642.

Hovland, C. I., Lumsdaine, A. A., \& Sheffield, F. D. (1949). Experiments in mass communication. Princeton, $\mathrm{NJ}$ : Princeton University Press.

Hovland, C. I., \& WEIss, W. (1952). Source credibility and effective communication. Public Opinion Quarterly, 16, 635-650.

Hyman, I. E., JR., HusBand, T. H., \& BillingS, F. J. (1995). False memories of childhood experiences. Applied Cognitive Psychology, 9, 181-197.

Johnson, M. K. (in press). Source monitoring and memory distortions. In L. Squire \& D. Schacter (Eds.), Biological and psychological perspectives on memory and memory disorders. New York: American Psychiatric Press.

LAMPINEN, J. M., \& SMith, V. L. (1995). The incredible (and sometimes incredulous) child witness: Child witnesses' sensitivity to source credibility cues. Journal of Applied Psychology, 80, 621-627.

LINDSAY, D. S. (1993). Eyewitness suggestibility. Current Directions in Psychological Science, 2, 86-89.

LofJus, E. F. (1993). The reality of repressed memory. American Psychologist, 48, 518-537.

LofTUS, E. F., \& Palmer, J. C. (1974). Reconstruction of automobile destruction: An example of the interaction between language and memory. Journal of Verbal Learning \& Verbal Behavior, 13, 585-589.

Loftus, E. F., \& Pickrell, J. E. (1995). The formation of false memories. Psychiatric Annals, 25, 720-725.

MazURSKY, D., \& SchUL, Y. (1987). The effects of advertisement encoding on the failure to discount information: Implications for the sleeper effect. Journal of Consumer Research, 15, 24-35.

Pezdek, K. (1977). Cross-modality semantic integration of sentence and picture memory. Journal of Experimental Psychology, 3, 515-524.

Pezdek, K., Finger, K., \& Hodge, D. (1997). Planting false childhood memories: The role of event plausibility. Psychological Science, $\mathbf{8}$, 437-441.

Pezdek, K., \& Greene, J. (1993). Testing eyewitness memory: Developing a measure that is more resistant to suggestibility. Law \& Human Behavior, 17, 361-369.

Pezdex, K., \& RoE, C. (1994). Memory for childhood events: How suggestible is it? Consciousness \& Cognition, 3, 374-387.

PEZDEK, K., \& ROE, C. (1995). The effect of memory trace strength on suggestibility. Journal of Experimental Child Psychology, 60, 116-128.

Smith, V. L., \& EllsworTh, P. C. (1987). The social psychology of eyewitness testimony: Misleading questions and communicator expertise. Journal of Applied Psychology, 72, 294-300.

(Manuscript received August 12, 1997; revision accepted for publication November 17,1997 .) 